\title{
THE RESONANT PHENOMENA IN A PNEUMATIC DRIVE PISTON
}

\author{
L.T. Raevskaia \\ Ural State Forest Engineering University (USFEU) \\ Sibirsky Tract, 37 \\ Ekaterinburg, 620100, Russia \\ ltrvsk@yandex.ru
}




\title{
THE RESONANT PHENOMENA IN A PNEUMATIC DRIVE PISTON
}

\begin{abstract}
We discuss the stability problem of a piston of the reversible axial-piston pneumatic motor called DAR-14M. We performed the full analysis of stress and deformation characteristics of the piston near a resonant frequency with the help of FEM ANSYS. We estimated the own frequency of the piston analytically for the given motor, this estimate was confirmed numerically in the model analysis FEM ANSYS. It was also shown in harmonic analysis that loaded piston end behaves very different in comparison to the unloaded end. As expected, maximum deformation was found in the area of the holes of the bearing shaft, indicating an optimization necessary in that region of the motor.
\end{abstract}

\section{KEYWORDS}

Frequency of a forced oscillation, axial - piston pneumatic motor, near resonance behaviour

\section{INTRODUCTION}

We consider reversible axial-piston air motor of DAR series, firstly engineered by Kaufman M.S. (1968). Such motors are widely used for power drive of underground mining machines: drilling rigs and carriages (Zhegalin, 1986), charging units in mining, loading and loading-transport machines, winches (Yashin, 1992). The motors of this kind are 1. 5-2 times smaller in weight and size than the radial-piston pneumatic ones. The bilateral action pistons create a torque of the rotor (Ankudinov, 1979). The rotor is a cam disk with two-way sinusoidal surface for converting reciprocal movement of the piston into rotation of the rotor. The piston makes three double movements along the rotor axis at the time of one full rotation of the rotor. Each piston has two bearings. The outer rings of the bearings are moving on sinusoidal profile surfaces of the rotor (that shown in Figure 1). This motion causes the rotor to move.

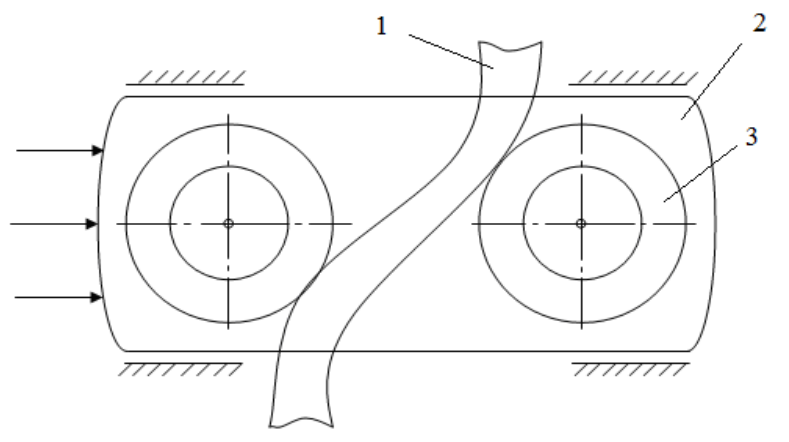

Figure 1- A scheme of the piston in assembly: 1 - the rotor, 2 - the piston, 3 - the bearing

In paper (Ankudinov, 1979) the main dynamic processes in rotor and piston group were investigated. The pressure in working chamber, the frequency of a rotor rotation, influence of the gap between the piston and a rotor on dynamics of engine, an acceleration of pistons were investigated. As a result of this 
analysis ways of engines improvement were outlined: use of more effective air filters and installation on the engine of bearings with bigger fatigue durability.

The bearings and the piston make a reciprocating movement jointly. Main drawbacks of these motors are a noise (Tauger, 1991) and a high rate of the piston breakages in an area of the holes for a bearing shaft ( $80 \%$ from all malfunctions) (Raevskaia, 2008). It is therefore useful to analyse the system behaviour under the influence of the periodic driving force. The study of resonant phenomena in the piston gives us the information about stability of our system. In our work we investigate the deformation problem, the stresses and the frequency of the piston own oscillation. We find, for example, an amplitude increase; sharp changes of the deformation intensity. A system can be destroyed when a frequency of the periodic driving force approaches to the system own frequency. We provide an estimate of such frequency depending on the system parameters.

\section{ENGINEERING DESIGN}

In reality deformed mechanical systems have an infinite number of degrees of freedom described by generalised coordinates. For analytical calculations it is necessary to limit this number by taking some justified approximations such as considering most rigid parts as absolutely undeformed. In our work we consider the piston's body in assembly as absolutely rigid in contrast to the bearing shaft. According to our estimates the bearing shaft stiffness coefficient is by two orders of magnitude less than the piston's stiffness coefficient. We take a rigidity of the shaft as the rigidity of an entire model system. The bearing shaft is subjected to bending deformation. Periodically changing pressure of compressed air pushes ends of the piston alternately. The piston makes oscillations. Thus external actions are the pressures in the working chamber $\mathrm{P}_{1}(\mathrm{t})$ and in the exhaust chamber $\mathrm{P}_{2}(\mathrm{t})$. Neglecting a friction of the sliding piston on cylindrical surface we got the following differential equation (Raevskaia, 2006)

$$
m x^{\prime \prime}+b\left(x^{\prime}-x_{0}^{\prime}\right)+c\left(x-x_{0}\right)=\pi d^{2}\left[P_{1}(t)-P_{2}(t)\right] / 4
$$

where $m$ is the piston mass; $x, x_{0}$ are the coordinates of the piston's butt-end central point before and after deformation respectively; $x^{\prime}-x_{0}^{\prime}$ is a relative movement velocity of this point; $d$ is a piston diameter; $c$ is a stiffness coefficient; $b$ is a damping coefficient. We obtain then a time dependence of the coordinate $x_{0}$

$$
x_{0}(t)=l_{I}+0,5 H(1-\cos \varphi(t))+\left(R_{0}-R_{D}\right)\left(D_{W}-A(t)\right) / A(t),
$$

where $l_{I}$ is an initial gap between end surface of the cylinder and the piston end face, $H$ is the piston stroke; $\varphi(t)$ is a varying angle of the sine curve piston's profile, $R o$ is a radius of the grinding wheel, $R_{D}$ is the piston radius, $D_{W}$ - average diameter of the rotor wave. Parameter $A(t)$ depends on the number $n$ of the sinusoid's waves:

$$
A(t)=\left(n^{2} H^{2} \sin ^{2} \varphi(t)+D_{W}{ }^{2}\right)^{1 / 2} .
$$

Taking into account dynamical loading in our calculations we obtain an estimate for the first resonance frequency approximately at $600 \mathrm{~Hz}$. For getting more accurate result we carry out numerical calculations using the finite element method. This method allows increasing manifold mechanical system's degrees of freedom and provides best dynamical analysis.

We've used the complete method of FEM ANSYS (Basov, 2005). The equations were solved by means of the sparse matrix method. We consider the homogenous piston of the pneumatic motor DAR14M. Technical data of the pneumatic motor DAR-14M: power - $10 \mathrm{~kW}$; rotational frequency - $400 \mathrm{r} / \mathrm{min}$; air pressure $-0.5 \mathrm{MN} / \mathrm{m}^{2}$; piston diameter - $0.082 \mathrm{~m}$; piston length $-0.160 \mathrm{~m}$; the hole diameter $-0.017 \mathrm{~m}$. The piston is molten (its alloy consists of Aluminum, Silicon - 7\% and Copper - 2\%). The alloy properties are: density $=2,800 \mathrm{~kg} / \mathrm{m}^{3}$; elasticity modulus $=71,000 \mathrm{MN} / \mathrm{m}^{2}$; Poisson coefficient $=0.31$. The own frequencies were found using the block Lanczos algorithm, which is much more efficient for large 
symmetric problems than the iteration method. The driving force amplitude was determined from the conditions of loading and was chosen as $\mathrm{P}=2,640 \mathrm{~N}$, yet the piston loaded by its own weight. All characteristics for the piston stress-strain state were calculated in every node of the finite elements grid (SOLID 92).

\section{RESULTS}

We used the Static Analysis to get a stress field, strain field and displacement field in the piston. We model the piston with its right loaded end. We determine a normal stress, a shear stress, and a principal stress. We analyze how these stresses vary with position throughout a piston. For example the Xaxial stress field is shown in Figure 2 (a). The principal stress field is shown in Figure 2 (b).

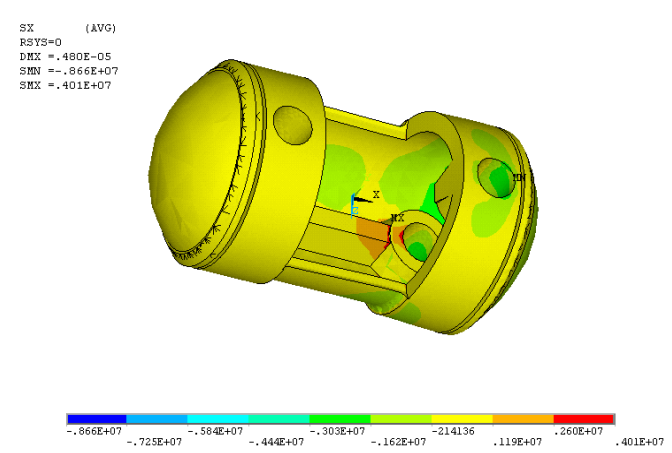

(a)

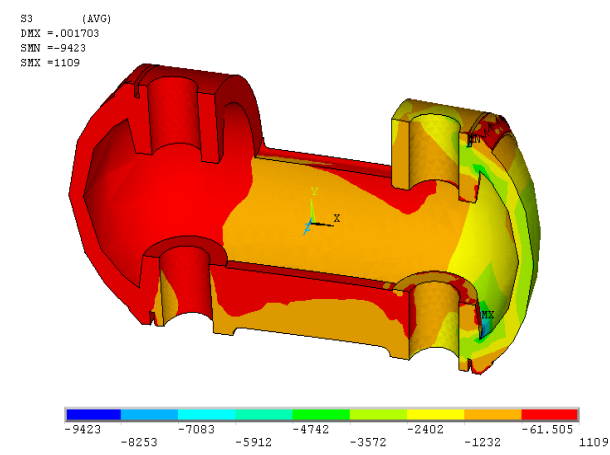

(b)

Figure 2- The normal stress field along $X$ axis in a piston body (a), the principal stress field (b)

One can see that a maximum stress appears near the holes for the bearing shaft as expected. This part of the piston is subjected to a deformation bending, and not only stretching and compression deformations. In order to decrease this deformation it is necessary to optimize the form and parameters of the stiffening rib.

The strain field is shown in Figure 3. Maximum deformation is in a stiffening rib and near the hole for a bearing shaft. See Figure (a), (b).

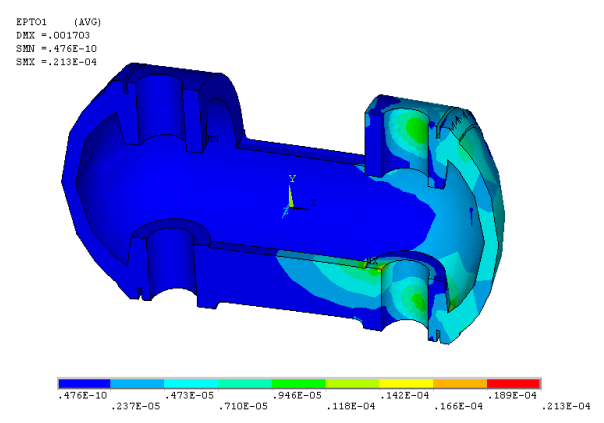

(a)

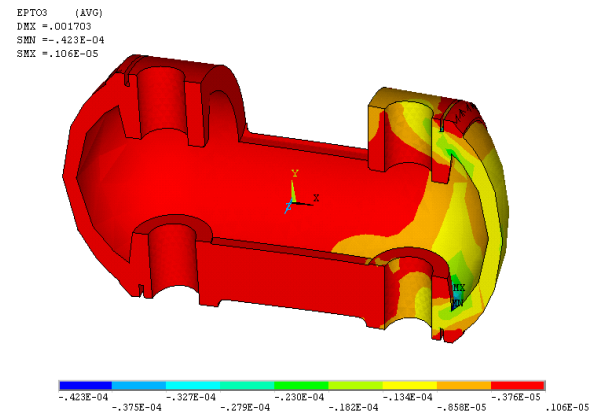

(b)

Figure 3- Total strain field, main total deformations $\varepsilon_{1}-(a), \varepsilon 3-(b)$ 
We used the Modal Analysis to get the own frequency of system and the vibrations modes. We obtained three first own frequencies and the corresponding oscillations. The results for the own frequencies are: $685.54 \mathrm{~Hz} ; 1053.8 \mathrm{~Hz} ; 2317.1 \mathrm{~Hz}$. Three first oscillation modes are shown in Figure 4. The elastic deformations for the first mode of oscillation about X-axis is shown in Figure (a), the second mode of oscillation about Z-axis is shown in Figure (b), the third mode of oscillation about Y-axis is in Figure (c). The axis $\mathrm{Z}$ is perpendicular to a surface of the figure.

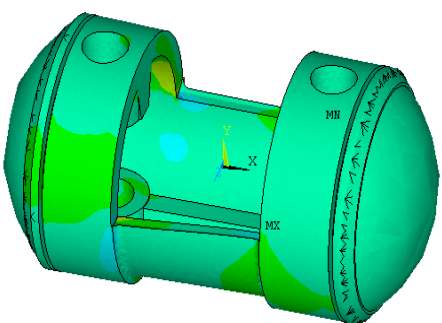

(a)

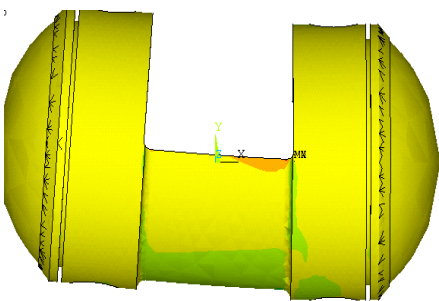

(b)

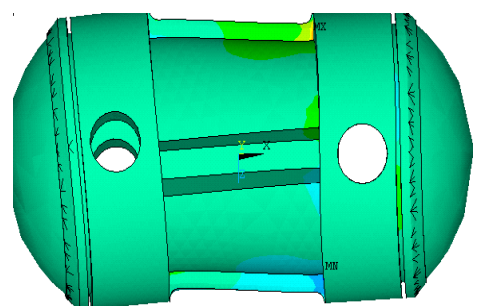

(c)

Figure 4 - First three own frequencies and oscillation modes: (a) - frequency $685.54 \mathrm{~Hz}$, (b) - frequency $1053.8 \mathrm{~Hz},(\mathrm{c})$ - frequency $2317.1 \mathrm{~Hz}$

The first resonance frequency turned out to be equal to $685 \mathrm{~Hz}$ in accordance with our analytical estimate.

We used the Harmonic Analysis to determine the piston behavior near the resonance. The load (pressure) was varied according to harmonic law and the system's response was considered at the frequencies interval $670-700 \mathrm{~Hz}$ with a step $6 \mathrm{~Hz}$. Some curves for the piston stress-strain state are shown in Figure 5.

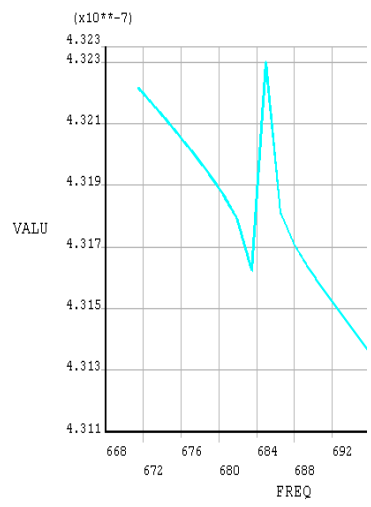

(a)

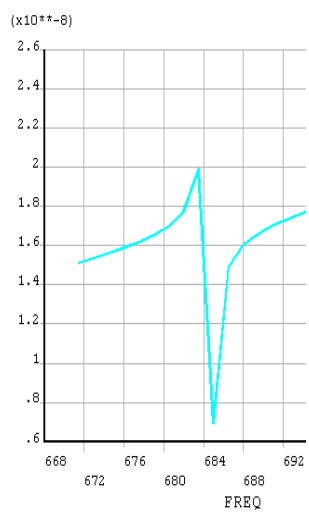

(b)

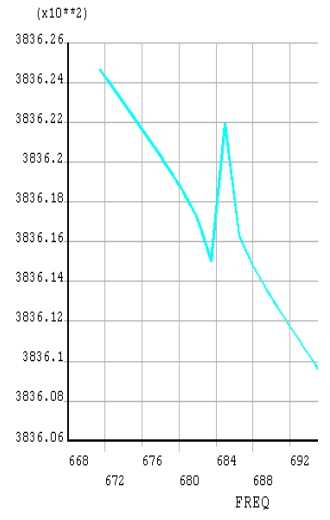

(c)

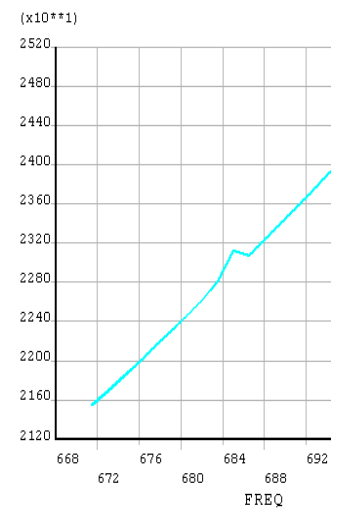

(d)

Figure 5 - XY- elastic deformation on the loaded sides (a), and on unloaded sides of the piston (b), the principal stress $\sigma_{1}<0\left(\mathrm{~N} / \mathrm{m}^{2}\right)$ on the loaded sides of the piston $(\mathrm{c})$, and the principal stress $\sigma_{1}>0\left(\mathrm{~N} / \mathrm{m}^{2}\right)$ on the unloaded sides of the piston (d) 


\section{DISCUSSION}

As a result we obtained all characteristics for the piston stress-strain state. The concentration of stresses is in the stiffening rib and near the hole for the bearing shaft. Peak dependencies were found for the stresses relative to coordinate axes, planes, and also principal stresses near the resonant frequency. Dependence of the normal stresses on the driving force frequency was different for central point of the loaded and unloaded piston's sides and at the same time in both cases we observed the stress-jumps. The stress of a central part of unloaded piston was slightly changed near the resonant frequency. Elastic deformations were also calculated to all directions and planes. We find the different behaviour for the loaded sides and unloaded sides of the piston near the resonant frequency.

\section{REFERENCES}

Kaufman, M. S. (1968). New axial-piston pneumatic. Coal and mining machinery. Mine transport. NII INFORM TYAJMASH, 21, 24-30. Sverdlovsk, USSR

Zhegalin, Ya. A., Feldsherov, V. I ., Charin, V.A., Denisov, I. B. (1986). The new KPN-4A complex for a driving of the rising. Gornyi Machines. Designing, calculation and researches of Mining machines.The scientific works. Ed. V.Ya.Zaslova and V.I. Feldsherov. NIPIGORMACH, Issue 19, pp. 33-39. Sverdlovsk, USSR.

Yashin, A. N., Ankudinov D. T. (1992). Machines and equipment for the mining industry and construction. Ural State Forest Engineering Institute, pp. 240. Ekaterinburg, Russia.

Ankudinov, D. T., Yefimov, M. V., Ivashov, I. V., Kudryavtsev, S. N. (1979). Research of dynamic processes in rotor and piston group of the pneumatic engine. Pneumatics and hydraulics. Drives and control systems. Issue 7. Ed. E.V.Gerts. Mechanical Engineering. pp. 77-83. Moscow, USSR.

Tauger, M. B. (1991). About efficiency of some ways to decrease a noise of DAR pneumomotors. Gornyi machines. Design, calculation and researches of Mining machines: NIPIGORMACH, Issue 20, pp. 204210. Sverdlovsk, Russia.

Raevskaia, L. T. (2008). Optimization of a rigidity edge for the pneumomotor piston. Izvestiya Vuzov. Gornyi Journal, No. 6, pp. 90 -94. Ekaterinburg, Russia.

Raevskaia, L. T. (2006). Dynamic modeling of the stress - deformed state of elements of axialpiston pneumatic. Woodworking: equipment, technology, management of XX1 century. The works of the Eurasian Symposium. Ed. I.T. Glebov. UGLTU. pp. 193-200. Ekaterinburg, Russia.

Basov, K. A. (2005). ANSYS: Directory of the user. DMK Press. pp. 640. Moscow, Russia. 